\title{
Diffuse Cavernous Hemangioma: Rectal Cancer Mimic
}

\author{
H. El Mortaji*, B. Boutakioute, M. Ouali Idrissi, N. Cherif Idrissi El Ganouni
}

Département de Radiologie, Hôpital Arrazi, CHU MED VI, Marrakech, Morocco

DOI: $10.36347 /$ sjmcr.2020.v08i10.010

| Received: 26.01.2020 | Accepted: 02.02.2020 | Published: 19.10.2020

*Corresponding author: El Mortaji Hajar

\section{Abstract}

Diffuse cavernous hemangioma of the rectum (DCHR) is a rare benign tumor of vascular origin. It affects mainly young adults. The clinical presentation is non-specific, therefore many patients are incorrectly diagnosed for several years. Imaging features may be helpful. CT can be predictive by showing phleboliths and MRI seems to be valuable and specific enough to make the diagnosis with certainty. We present a case of a 53-year old male patient with a history of recurrent and painless rectal bleeding evolving for 5 years who was finally diagnosed of diffuse cavernous hemangioma of the rectum.

Keywords: Diffuse cavernous hemangioma of the rectum, MRI, CT.

Copyright $(\mathcal{2 0 2 0}$ The Author(s): This is an open-access article distributed under the terms of the Creative Commons Attribution 4.0 International License (CC BY-NC 4.0) which permits unrestricted use, distribution, and reproduction in any medium for non-commercial use provided the original author and source are credited.

\section{INTRODUCTION}

Diffuse cavernous hemangioma of the rectosigmoid colon is an uncommon disease that affects mainly young adults. The rectosigmoid is the most common site of this disease in the gastrointestinal tract. The clinical presentation includes usually acute, recurrent or chronic rectal bleeding. Symptoms usually manifest early in the disease, in some cases the diagnosis is established until adulthood as is the case of our patient [1].

\section{Case Report}

A 53-year-old male patient was admitted in our radiology department with a history of recurrent and painless rectal bleeding. On examination, he has a pale skin and a normal abdominal examination.

Endoscopic examination showed an oedematous and congested appearance of the rectal mucosa.

MRI showed a circumferential diffuse rectal thickening of the mucosal wall that was in hyposignal on T1W image (Figure-1), in hyper signal on T2W image with no restriction of diffusion (Figure $2 \& 3$ ). The mucosal wall demonstrated a progressive enhancement over the different vascular times.
Increased signal intensity is also noted in the perirectal fat with serpiginous structures correlating to the small vessels supplying the hemangioma (Figure-4). An abdominal CT performed later was more contributive by showing in addition to the thinckening of the rectal wall, phleboliths in the mesorectal fat (Figure-5).

The diagnosis of diffuse cavernous hemangioma of the rectum was strongly suspected. The patient was under a simple observation for 5 years with a favorable evolution.

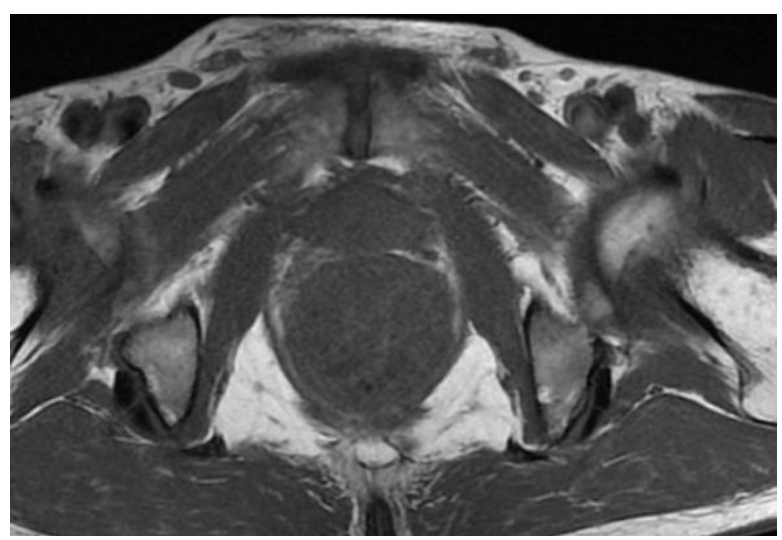

Fig-1: T1-weignted awial view showing a thickening of the rectal wall in hyposignal 

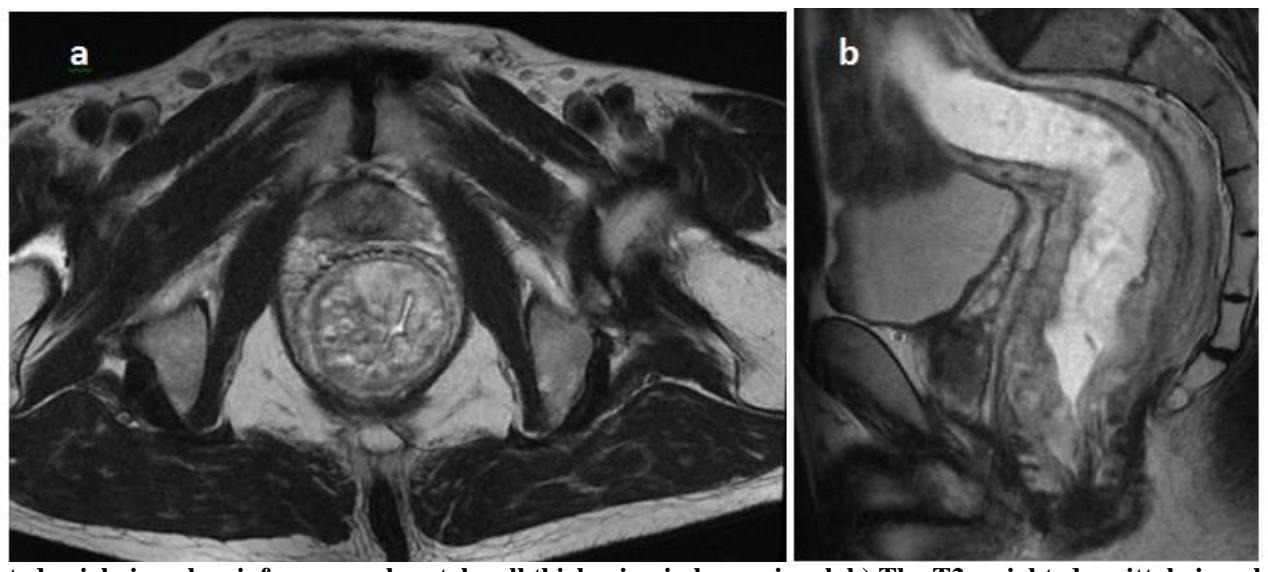

Fig-2: a) T2-weighted axial view showinf a mucosal rectal wall thickening in hypersignal. b) The T2-weighted sagittal view shows the extension of the thikness that covers all of the rectal wall
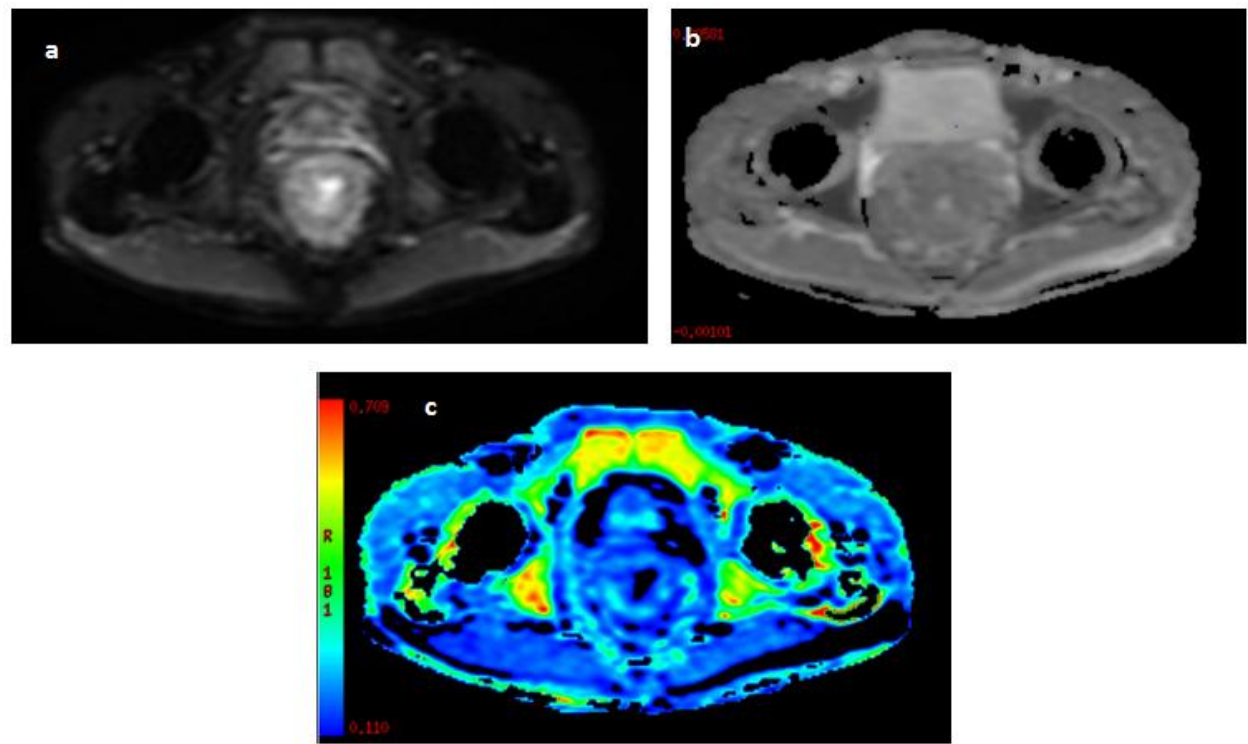

Fig-3: Diffusion weighted imaging views showing no restriction within the mucosal wall
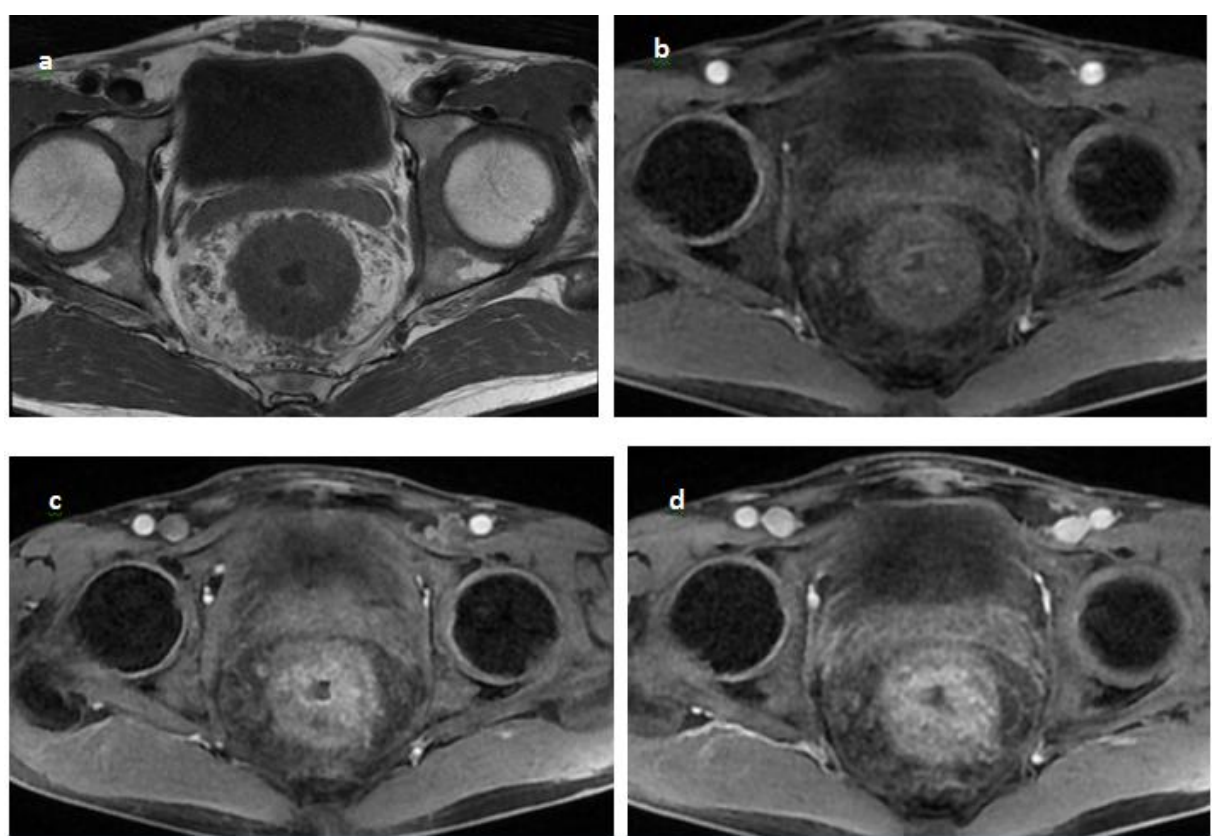

Fig-4: T1 weighted axial view without contrast (a) showing the mucosal wall thickening and serpiginous structures within the perirectal fat. T1 weighted axial views with contrast $(b, c, d)$ demonstrates a progressive enhancement over the different vascular times. Note the increased signal intensity in the perirectal fat as well 

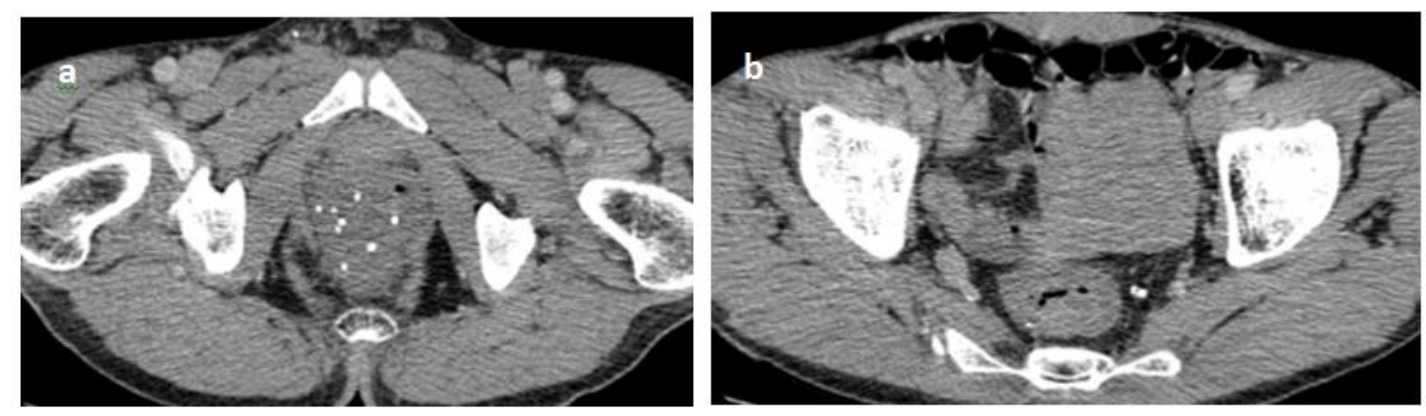

Fig-5: CT axial view without contrast showing calcifications within the rectal wall thickening (a) and the perirectal fat (b)

\section{DISCUSSION}

Diffuse cavernous hemangioma of the rectosigmoid colon was reported for the first time by Philip in 1839 [2].

So far approximately 200 such cases have been reported in the literature [3].

Pathogenesis of this disorder has not been fully elucidated [2]. Formation of DCHR is suspected to stem from abnormal development of mesodermal tissue in the prenatal period $[3,4]$.

Cavernous hemangiomas are composed of large thin-walled vascular channels and have no capsule. The characteristic phleboliths arise because of thrombosis from inflammation or stasis [5].

Similar lesions may also coexist in the skin, central nervous system, and elsewhere in the gastrointestinal tract and accessory organs of digestion. Full-thickness mural involvement is typical, often with infiltration into the surrounding connective tissue and occasionally into adjacent organs [6].

Most commonly DCHR is diagnosed in patients between 5 and 25 years of age [2]. The clinical presentation of DCHR is non-specific. Patients come with a history of multiple, painless, rectal bleeding episodes or an episode of massive, life threatening gastrointestinal bleeding and anemia $[2,7]$.

As a result, many patients are incorrectly diagnosed. DCHR has been frequently mistaken for internal hemorrhoids, ulcerative colitis, or adenomatous polyp. Jeffery et al., [8] found that $80 \%$ of patients with DCHRC had had at least one surgical procedure performed because of an incorrect clinical diagnosis.

On endoscopy, cavernous hemangiomas characteristically present as nodular, compressible lesions that are deep blue to dull red and are associated with mucosal congestion and edema. Unfortunately, chronic inflammatory changes often mask findings that could lead to proper diagnosis. Biopsy may cause profuse hemorrhaging, partially because of decreased smooth muscle in the abnormal vascular channels and should be performed carefully [9].
Pathognomonic findings on the CT consist of inhomogeneously enhancing transmural bowel-wall thickening containing phleboliths.

A primary advantage of choosing CT over endoscopy is that wall thickening and extramural extension can be accurately evaluated. In fact, many mimicking lesions on endoscopy are mucosal inflammatory processes, most of which would be excluded by the visualization of transmural wall thickening on CT [9].

The MR imaging features show an intermediate signal intensity with some bright foci on MRI T1-weighted images. Characteristically, hemangioma demonstrates heterogeneous bright signal intensity on T2-weighted images and it is more clearly depicted with fat suppression. Calcifications are usually signal-voided on both T1- and T2-weighted images. Thrombosed vessels are depicted as tubular structures with high signal intensity on MRI. The advantage of MRI is that it can provide detailed multiplanar anatomical images, it can also specify sphincteric involvement and the involvement of the adjacent structures. Hemorrhoids should be considered in the differential diagnosis. Hemorrhoids usually involve only the anal region. Perirectal fat abnormalities and marked bowel wall thickening are not seen in hemorrhoids, and are easily shown by MR imaging. T2WI hyperintensity may be seen in severe inflammatory conditions such as Crohn's disease, ulcerative colitis but also in cancer too. Yet those diseases accompany significant colon wall enhancement and the ADC is low for the malignant tumors [10]. Thus, MR imaging features of diffuse cavernous hemangioma of the rectosigmoid colon seem valuable and specific enough to make MR imaging a non invasive and accurate diagnostic tool, especially when the endoscopy with biopsy are negative [11].

Once a diagnosis has been established, eradication of the lesion should be recommended. Although alternative therapies such as sclerotherapy, criotherapy or argon fulguration have been used, these procedures are only of limited value in the case of welldefined, small lesions; because of this, most authors 
have been abandoned these treatment nowadays for surgical procedures [12].

\section{Conclusion}

Cavernous hemangiomas of the rectm, although uncommon, are important for radiologists to recognize. Accurate radiologic diagnosis is crucial if a biopsy — which may cause catastrophic hemorrhagingis to be avoided. Patients with cavernous hemangiomas usually present with rectal bleeding and often undergo a variety of diagnostic tests. MR imaging features of diffuse cavernous hemangioma of the rectosigmoid colon seem valuable and specific enough to make MR imaging a non invasive and accurate diagnostic tool. CT can also help by showing calcifications and phleboliths wich are less easily detected by MRI.

\section{REFERENCES}

1. Sylla P, Deutsch G, Luo J, Recavarren C, Kim S, Heimann TM, Steinhagen RM. Cavernous, arteriovenous, and mixed hemangiomalymphangioma of the rectosigmoid: rare causes of rectal bleeding - case series and review of the literature. International journal of colorectal disease. 2008 Jul 1;23(7):653-8.

2. Hakeem AA, Shafi H, Gojwari T, Shaheen F, Singh M, Wani M, Rasool S. CT findings in diffuse rectosigmoid cavernous heamangioma. A case report. Journal of Gastrointestinal Surgery. 2009 May 1;13(5):1017-8.

3. Stojčev Z, Maliszewski D, Pawłowska-Stojčev I, Kasprzyk T, Jaśkiewicz J. Diffuse cavernous hemangioma of the rectum (DCHR)-diagnosis and treatment-case report and review of available literature. Polish Journal of Surgery. 2013 Apr $1 ; 85(4): 216-8$.

4. Vilallonga R, Espin Basany E, Armengol M. Cavernous hemangioma: Unusual benign tumor of the transverse colon. Turk J Gastroenterol. 2009 Jun 1;20(2):146-9.

5. Djouhri H, Arrivé L, Bouras T, Martin B, Monnier-Cholley L, Tubiana JM. Diffuse cavernous hemangioma of the rectosigmoid colon: imaging findings. Journal of computer assisted tomography. 1998 Nov 1;22(6):851-5.

6. Fenlon HM, Nunes DP, Schroy PC, Barish MA, Clarke PD, Ferrucci JT. A comparison of virtual and conventional colonoscopy for the detection of colorectal polyps. New England Journal of Medicine. 1999 Nov 11;341(20):1496-503.

7. Żurakowski J, Świercz P, Wróblewski T, Paluszkiewicz R, Patkowski W, Smoter P, Dudek $\mathrm{K}$, Leonowicz D, Nawrot I, ZiarkiewiczWróblewska B, Szmidt J. Diffuse cavernous hemangioma of rectosigmoid colon treated with nbutyl-2-cyanoacrylate injections. Endoscopy. 2008 Dec;40(S 02):E120-121.

8. Bortz JH. Diffuse cavernous hemangioma of the rectum and sigmoid. Abdominal imaging. 1994 Jan 1;19(1):18-20.

9. Hsu RM, Horton KM, Fishman EK. Diffuse cavernous hemangiomatosis of the colon: findings on three-dimensional CT colonography. American Journal of Roentgenology. 2002 Oct;179(4):10424.

10. Yorozuya K, Watanabe M, Hasegawa H, Baba H, Imai Y, Mukai M, Kitajima M. Diffuse cavernous hemangioma of the rectum: report of a case. Surgery today. 2003 Apr 1;33(4):309-11.

11. Kandpal H, Sharma R, Srivastava DN, Sahni P, Vashisht S. Diffuse cavernous haemangioma of colon: magnetic resonance imaging features. Report of two cases. Australasian radiology. 2007 Oct;51:B147-51

12. Zeng Z, Wu X, Chen J, Luo S, Hou Y, Kang L. Safety and Feasibility of Transanal Endoscopic Surgery for Diffuse Cavernous Hemangioma of the Rectum. Gastroenterology Research and Practice. 2019;2019. 